\title{
Implications of the local hemodynamic forces on the formation and destabilization of neoatherosclerotic lesions
}

Ryo Torii, ${ }^{1} \mathrm{PhD}$; Rodrigue Stettler, ${ }^{2} \mathrm{MD}$; Lorenz Räber, ${ }^{3} \mathrm{MD}$, PhD; Yao-Jun Zhang, ${ }^{4} \mathrm{MD}$, PhD; Antonis Karanasos, ${ }^{5}$ MD PhD; Jouke Dijkstra, ${ }^{6}$ PhD; Kush Patel, ${ }^{2}$ MBBS; Tom Crake, ${ }^{2}$ MD, FRCP; Steve Hamshere, ${ }^{2}$ MBBS; Hector M. Garcia-Garcia, ${ }^{5} \mathrm{MD}$, PhD; Erhan Tenekecioglu, ${ }^{5} \mathrm{MD}$, PhD; Muhiddin Ozkor, ${ }^{2} \mathrm{MD}$, BSc; Andreas Baumbach, ${ }^{2,7} \mathrm{MD}$, FRCP; Stephan Windecker, ${ }^{3}$ MD; Patrick W. Serruys,${ }^{5,8} \mathrm{MD}$, PhD; Evelyn Regar, ${ }^{5} \mathrm{MD}, \mathrm{PhD}$; Anthony Mathur, ${ }^{2,7} \mathrm{MD}$, $\mathrm{PhD}$; Christos V. Bourantas, ${ }^{2,7,9, *} \mathrm{MD}, \mathrm{PhD}$

${ }^{1}$ Department of Mechanical Engineering, University College London, London, United Kingdom

${ }^{2}$ Barts Heart Centre, Barts Health NHS, London, United Kingdom

${ }^{3}$ Bern University Hospital, Bern, Switzerland

${ }^{4}$ Nanjing First Hospital, Nanjing Medical University, Nanjing, China

${ }^{5}$ Thoraxcenter, Erasmus Medical Centre, Rotterdam, The Netherlands

${ }^{6}$ Leiden University Medical Centre, Leiden, The Netherlands

${ }^{7}$ Queen Mary University London, London, United Kingdom

${ }^{8}$ Faculty of Medicine, National Heart \& Lung Institute, Imperial College London, United Kingdom

${ }^{9}$ Institute of Cardiovascular Sciences, University College London, London, United Kingdom

\section{Conflict of interest: None}

Funding: This work was supported from Barts Charity and St Jude Medical.

Keywords: Neoatherosclerosis; endothelial shear stress; optical coherence tomography.

*Address for correspondence

Christos V. Bourantas, MD, PhD: Consultant cardiologist Barts, Heart Centre, $1^{\text {st }}$ St Martin's le Grand, London EC1A 7BE, United Kingdom e-mail: Christos.Bourantas@bartshealth.nhs.uk;

Tel: +44 208535 6736, Fax: +44 2085356690 


\section{Abstract}

Objective: To examine the implications of endothelial shear stress (ESS) distribution in the formation of neoatherosclerotic lesions.

Methods: Thirty six patients with neoatherosclerotic lesions on optical coherence tomography (OCT) were included in this study. The OCT data were used to reconstruct coronary anatomy. Blood flow simulation was performed in the models reconstructed from the stent borders which it was assumed that represented the lumen surface at baseline, immediate after stent implantation, and the estimated ESS was associated with the neointima burden, neoatherosclerotic burden and neointima characteristics. In segments with neointima rupture blood flow simulation was also performed in the model representing the lumen surface before rupture and the ESS was estimated at the ruptured site.

Results: An inverse association was noted between baseline ESS and the incidence and the burden of neoatherosclerotic $(\beta=-0.60, \mathrm{P}<0.001$, and $\beta=-4.05, \mathrm{P}<0.001$, respectively $)$ and lipid-rich neoatherosclerotic tissue $(\beta=-0.54, \mathrm{P}<0.001$, and $\beta=-3.60, \mathrm{P}<0.001$, respectively). Segments exposed to low ESS $(<1 \mathrm{~Pa})$ were more likely to exhibit macrophage accumulation $(28.2 \%$ vs $10.9 \%, \mathrm{P}<0.001)$, thrombus $(11.0 \%$ vs $2.6 \%, \mathrm{P}<0.001)$ and evidence of neointima discontinuities $(8.1 \%$ vs $0.9 \%, \mathrm{P}<0.001)$ compared to those exposed to normal or high ESS. In segments with neointima rupture the ESS was high at the rupture site compared to the average ESS over the culprit lesion $(4.00 \pm 3.65 \mathrm{~Pa} v \mathrm{~s}$ $3.14 \pm 2.90 \mathrm{~Pa}, \mathrm{P}<0.001)$.

Conclusions: Local EES is associated with neoatherosclerotic lesion characteristics, which suggests involvement of ESS in the formation of vulnerable plaques in stented segments. 


\section{Introduction}

Local hemodynamic forces and in particular endothelial shear stress (ESS) appear to regulate atherosclerotic evolution in native coronary arteries. Experimental studies have shed light onto the mechanotransduction processes that regulate plaque formation and provided robust evidence that ESS is involved in the formation of high-risk vulnerable lesions, while clinical studies demonstrated that ESS is also a predictor of lesions that are likely to progress and cause cardiovascular events.[1]

In stented segments short-term follow-up intravascular imaging studies have shown that ESS determines neointima proliferation in bare metal stents (BMS) and bioresorbable scaffolds, while in drug eluting stents (DES) this effect- at least at short-term - is inhibited by the antiproliferative drug.[2-3] However, to date there are no data about the longterm implications of the local hemodynamic forces on neointima growth and about their role in the formation of neoatherosclerotic lesions. The objectives of this study are: 1) to examine the role of the ESS on the formation of neoatherosclerotic plaques and 2) its implications on neoatherosclerotic plaque destabilization.

\section{Methods}

\section{Patient population}

This is a retrospective analysis of optical coherence tomographic (OCT) data acquired from patients with neoatherosclerotic lesions that underwent OCT imaging for suspected stent failure. Five experts (RS, LR, AK, YZ and CB) reviewed the OCT databases in four University Hospitals (St Bartholomew Hospital Barts Health NHS Trust, Bern University Hospital, Nanjing First Hospital and Thoraxcentre Erasmus MC) and identified consecutive patients with neoatherosclerotic lesions that had OCT imaging for suspected stent failure. All the recruited patients had complete assessment of the stented segment with Fourier Domain OCT before balloon pre-dilation. OCT examinations with poor imaging quality, and extensive thrombus or extensive neointima disruptions that did not allow accurate delineation of the lumen were excluded from the analysis. In addition, segments implanted with different stent types (i.e., with BMS and DES or with a $1^{\text {st }}$ and $2^{\text {nd }}$ generation DES), segments with extensive stent overlapping $(>5 \mathrm{~mm})$ and those where the stent border could not be assessed for a circumference of $>180^{\circ}$ in a length $>0.8 \mathrm{~mm}$ were excluded from the analysis of the effect of ESS on neoatherosclerotic lesion formation. Segments that exhibited neointima rupture - even those with extensive overlapping and those where the stent border was not visible in the entire pullback - were used to examine the implications of ESS on neointima destabilization (supplementary Figure 1). 
Sirolimus (Cypher, Cordis, Miami Lakes, FL) and Paclitaxel (Taxus, Boston Scientific, Natick, MA) eluting stents were classified as $1^{\text {st }}$ generation DES, while Zotarolimus (Endeavor Sprint or Resolute, Medtronic, Santa Rosa, CA), Biolimus (BioMatrix, Biosensors Inc, Singapore), and Everolimus (Xience, Abbott Vascular, Abbott Park, IL) as $2^{\text {nd }}$ generation DES. Segments implanted with a stent of unknown type were also excluded from the analysis.

\section{Optical coherence tomography - data acquisition}

OCT imaging was performed with a C7XR, an OPTIS ${ }^{\mathrm{TM}}$ (St-Jude Medical, Westford, MA, USA) or a Lunawave (Terumo Corp, Tokyo Japan) Fourier Domain system. In segments with increased thrombus burden, thrombus aspiration was undertaken before OCT imaging. Pull-back was performed with the use of an automated pull-back device at a constant speed (range: $18-40 \mathrm{~mm} / \mathrm{s}$ ) during continuous injection of contrast medium (frame rates: $180 \mathrm{fr} / \mathrm{s}$ for the OPTIS, $100 \mathrm{fr} / \mathrm{s}$ for the C7XR and $160 \mathrm{fr} / \mathrm{s}$ for the Lunawave system).

\section{Segmentation of optical coherence tomographic data}

OCT imaging analysis was performed offline using proprietary software (QCM-CMS Medis Medical Imaging System, Leiden, The Netherlands). The stented segments were identified and the most proximal and distal side branches that were visible in both OCT and X-ray angiographic images were detected and used to define the segment of interest. The OCT frames portraying this segment were analysed at $0.4 \mathrm{~mm}$ interval $(0.375 \mathrm{~mm}$ for the Lunawave system) by two independent analysts (RS and CB) blinded to stent type and patients' characteristics. The lumen borders in the nonstented segment of interest and the lumen and stent borders - defined by a curve connecting the hyper-intense signal of the metallic struts - in the stented segment were detected. Neointima was defined as the tissue between the lumen and stent border. Similar to previous studies investigating the effect of ESS on plaque rupture in frames with neointima discontinuities (supplementary file) an additional border was drawn that connected the edges of the ruptured fibrous cap and represented the lumen surface before neointima rupture. [4]

Neoatherosclerosis was defined as neointima with lipid and/or calcific tissue. In frames with neoatherosclerotic lesions the lipid and calcific tissue borders were detected and their areas were estimated (supplementary file). In addition, the minimum cap thickness was estimated and used to classify the neoatherosclerotic plaques as thin (TCFA, minimum cap thickness $\leq 65 \mu \mathrm{m}$ ) or thick cap fibroatheromas (minimum cap thickness $>65 \mu \mathrm{m}$ ). Finally, the presence of thrombus, macrophage accumulations, neo-vessels and cholesterol crystals were detected (supplementary file). 


\section{Reconstruction of coronary anatomy}

A well established and validated methodology was used to reconstruct the segments of interest.[5] In brief, this approach involves the extraction of the luminal centreline from 2 angiographic projections, the placement of the OCT borders onto the luminal centreline and the estimation of the absolute orientation of the OCT borders using established algorithms that take into account the origin of side branches identified in both OCT and angiographic projections. The OCT data acquired at the time of the event was used to reconstruct two models for each studied vessel: the first was reconstructed from the lumen borders in the non-stented segment and the stent borders in the stented segment, and it was assumed to represent the lumen surface at baseline immediately after stent implantation (baseline model), and the second from the lumen borders both in the stented and non-stented segments and corresponded to the lumen geometry at follow-up (follow-up model). In addition, in segments with neointima discontinuities, a third model was reconstructed from the lumen borders before neointima rupture and this represented the lumen geometry before the cardiovascular event (pre-rupture model). More specifically, similar to previous studies investigating the effect of ESS on plaque rupture, in frames portraying neointima rupture we approximated the lumen border before rupture by drawing an arc that connected the edges of the ruptured fibrous cap. [4] Blood flow simulation was performed at the baseline and the pre-rupture models and the ESS was estimated (supplementary file).

\section{Data analysis}

Analysis was restricted in the stented segment. Each stented segment in each reconstructed artery was divided into consecutive 1.5-mm sub-segments and for each sub-segment the minimum predominant ESS was estimated at the baseline model as previously described. [2] In addition, for each $1.5 \mathrm{~mm}$ segment the mean lumen area, the mean stent area, the mean neointima area and burden (defined as: $100 \times$ neointima area / stent area), the mean lipid tissue and calcific tissue area and burden and the minimum cap thickness over lipid tissue - defined as the minimum thickness of the fibrous cap in the $1.5 \mathrm{~mm}$ sub-segment-were estimated.

In stented segments with neointima discontinuities, neointima ruptures - indicated by the presence of a cavity or a flap on OCT - were identified. We define as a ruptured lesion a segment that had neointima rupture and exhibited a maximum stenosis (throat), two shoulders and an upstream and downstream segment. The upstream and downstream segments were characterised as segments exhibiting progressive narrowing from their distal end towards the throat. The most 
proximal and distal to the throat OCT frames that had a mean neointima thickness $>0.5 \mathrm{~mm}$ were assumed that corresponded to the proximal and distal end of the ruptured lesion. [4] To examine the effect of ESS on plaque rupture we performed blood flow simulation in the pre-rupture model and estimated the local ESS - not the predominant - at the rupture site and compared them with the average ESS at the ruptured lesion and the average luminal ESS at the remaining stented segment. $[4,6]$

\section{Statistical analysis}

Continuous variables are reported as mean \pm standard deviation when they are normally distributed and median and interquartile range (IQR) when they are not normally distributed. Categorical values are presented as absolute value and percentage. Anova and Kruskal-Willis test - depending on variables' distribution - were used for independent group comparison of continues variables and chi-square test was used to compare categorical variables. In order to examine associations between the minimum predominant ESS and OCT-derived variables in 1.5mm sub-segments, linear-mixed effect models were used: stent type and stent cross-sectional area were considered as fixed factors, and each individual patient was considered as random effect to account for intra-individual dependency. For the binomial dependent variables such as presence of neoatherosclerosis in a segment, generalised mixed-effect models (logistic regression) were used. A P-value $<0.05$ was considered statistical significant. Analysis was performed with the SPSS 20 (SPSS Inc, Chicago, IL) and the open-source R (version 3.3.0) statistical packages.

\section{Results}

\section{Patients' characteristics}

From November 2009 till June 2016, 43 patients were deemed suitable for inclusion in the study. After reviewing the data, 36 patients (36 segments: 11 implanted with a BMS, 12 with a $1^{\text {st }}$ generation DES and 13 with a $2^{\text {nd }}$ generation DES) were included in the study, of which 34 in the analysis that investigated the association between neoatherosclerosis and ESS distribution (supplementary Figure 1). Two patients were excluded because of lack of optimal angiographic projections that are required for the reconstruction of coronary anatomy, 1 because of extensive overlapping, 1 because of no neoatherosclerotic lesions, 1 because of the fact that the stent type was not known and 2 because it was not possible to accurately delineate the stent borders. 
From the 36 patients that were included in the analysis, 30 had an event because of a neoatherosclerotic lesion (10 exhibited neointima rupture and 20 significant restenosis because of a neoatherosclerotic plaque), 2 had an event because of restenosis attributed to excessive neointima proliferation and 4 did not have significant in stent restenosis.

The effect of the local hemodynamic forces on neointima rupture was assessed in 10 segments; in 8 segments that were included in neoatherosclerosis analysis and in 2 segments, implanted with a $2^{\text {nd }}$ generation DES, that were excluded from the neoatherosclerosis analysis because of extensive stent overlapping or increased lipid-rich neointima that did not allow visualization of the stent border in a segment with length $>0.8 \mathrm{~mm}$; in the latter case OCT imaging allowed identification of the upstream and downstream borders of the ruptured lesion.

The baseline characteristics of the patients included in the neoatherosclerosis analysis at the time of their enrolment in this study are shown in Table 1. Most of the patients suffered from hypertension and were admitted with an acute coronary syndrome. The time interval between the index procedure and the cardiovascular event was increased in patients implanted with BMS while the patients treated with a $2^{\text {nd }}$ generation DES received longer stents. There were no other differences in the baseline demographics between patients implanted with different stent types.

\section{Neointima characteristics and ESS distribution in different stent types}

Neointima characteristics and minimum predominant ESS were estimated in $5841.5 \mathrm{~mm}$ sub-segments (148 implanted with a BMS, 168 with a $1^{\text {st }}$ and 268 with a $2^{\text {nd }}$ generation DES). As it is shown in Table 2, the lumen, stent, neointima area and burden, and the ESS distribution were similar in different stent types; nevertheless the incidence of neoatherosclerosis, and of TCFA was increased, in BMS compared to $1^{\text {st }}$ and $2^{\text {nd }}$ generation DES.

\section{Association between ESS distribution and neointima characteristics}

There was an inverse association between baseline ESS and neointima area and burden (supplementary Figure 2, Table

3). The incidence of neoatherosclerosis, lipid-rich and calcific rich neointima was higher in segments exposed to low baseline ESS compared to segments with higher ESS. Low baseline ESS was associated with increased neoatherosclerotic and lipid-rich tissue area and burden but there was no association between ESS and calcific burden. Of note in $65.5 \%$ of the segments with calcific-rich neointima the calcific tissue extended behind the stent border indicating that the underlying plaque may also be an instigator of neointima calcification (supplementary Figure 3). 
TCFA, neo-vessels, cholesterol crystals, the minimum thickness of the fibrous cap and the incidence of discontinuities were not associated with the baseline ESS. Conversely, low predominant ESS at the baseline appeared to promote neointima inflammation and macrophage accumulations. Sub-segments exposed to low ESS at baseline were also more likely have thrombus at follow-up. Stent type did not have an effect on the association between ESS and neoatherosclerotic characteristics ( $\mathrm{P}>0.05$ for all the studied variables).

Similar results were obtained when the baseline ESS was treated as categorical value. Segments exposed to low baseline ESS $(<1 \mathrm{~Pa})$ were more likely to exhibit neoatherosclerotic [110 (40.3\%) vs $81(26.0 \%), \mathrm{P}<0.001]$ and lipid-rich tissue [84 (30.8\%) vs 55 (17.7\%), $\mathrm{P}<0.001$ ], macrophage accumulations [77 (28.2\%) vs 34 (10.9\%), $\mathrm{P}<0.001]$, thrombus [30 (11.0\%) vs 8 (2.6\%), $\mathrm{P}<0.001$ ] and neointima discontinuities [22 (8.1\%) vs3 (0.9\%), $\mathrm{P}<0.001$ ] but there were no differences between the ESS groups in the incidence of the calcific-rich neointima [29 (10.6\%) v s29 (9.3\%), $\mathrm{P}=0.700$; Figure 1].

\section{Implications of ESS on neointima destabilization}

The baseline characteristics of the 10 patients who exhibited neointima rupture are shown in supplementary Table 1. Increased neointima burden was reported at the rupture site $(65.0 \pm 17.7 \%)$ that caused lumen obstruction (minimum lumen area: $2.60 \pm 1.73 \mathrm{~mm}^{2}$, stent area: $6.86 \pm 1.59 \mathrm{~mm}^{2}$ and neointima area: $4.25 \pm 0.78 \mathrm{~mm}^{2}$ ). Macrophages accumulations were seen at the ruptured site in $70 \%$ of the cases. The length of the rupture site was $2.64 \pm 1.10 \mathrm{~mm}$ (range: 0.80 $7.40 \mathrm{~mm}$ ). Figure 1 shows the location of the maximum rupture; only one rupture was located upstream of the ruptured lesion, none downstream, 6 at the throat and 3 at the shoulders of the lesion. When we characterise the location of the rupture based on the $1^{\text {st }}$ frame showing neointima discontinuity, in 2 lesions the rupture was located upstream, in 5 at the throat and in 3 at the shoulders of the lesion. Only one rupture was located upstream of the ruptured lesion, none in the downstream, 7 at the throat of the lesion and 2 at the shoulders of the lesion. The average ESS was higher in these lesions compared to ESS in the remaining segment (3.14 $\pm 2.90 \mathrm{~Pa} v s 1.21 \pm 1.15 \mathrm{~Pa}, \mathrm{P}<0.001$; Figure 2). At the rupture site

the local ESS was considerably higher than the average ESS in the ruptured lesion $(4.00 \pm 3.65 \mathrm{~Pa} v s 3.14 \pm 2.90 \mathrm{~Pa}$, $\mathrm{P}<0.001)$. 


\section{Discussion}

In this study we examined for the first time the role of ESS on the generation and destabilization of neoatherosclerotic lesions. We analyzed OCT data from patients undergoing intravascular imaging for suspected stent failure and we demonstrated that: 1) irrespective of the stent type there is an inverse association between neointima formation and baseline ESS, 2) stented segments exposed to low ESS at baseline were more likely to develop lipid-rich neoatherosclerotic lesions than those exposed to normal or high ESS, 3) there was a significant inverse association between low ESS and macrophage accumulations, 4) neointima discontinuities and thrombus were seen more often in segments exposed to low baseline ESS ( $<1 \mathrm{~Pa})$ and 5) in segments with neointima rupture the ESS was high at the rupture site indicating that high ESS contributes to the destabilization of neoatherosclerotic lesions.

Over the past years several studies have examined the association between ESS and neointima formation in BMS, DES and bioresorbable scaffolds, demonstrating an inverse association between neointima proliferation and ESS in BMS and bioresorbable scaffolds while in DES the limited neointima detected in these segments did not allow the drawing of firm conclusions, although small scale studies did show that ESS may regulate neointima formation especially in paclitaxeleluting stents. $[2-3,7-8]$ Of note in all the previous studies intravascular imaging was performed at short-term followup $(<13$ months $)$ where neointima proliferation is suppressed by the antiproliferative drug. In the present report, we examined for the first time the long-term implications of ESS on neointima proliferation and showed that, irrespective of the stent type, ESS is a predictor of neointima formation indicating that the local hemodynamic forces regulate not only early neointima response in BMS but also the delayed neointima proliferation noted in DES - the so called late catch up phenomenon. [9]

Several histology and intravascular-based imaging studies have recently shed light onto the mechanisms involved in neoatherosclerotic lesion formation demonstrating that not only systemic but also local factors - i.e., the composition of the underlying plaque, local inflammation and endothelial dysfunction, which can be precipitated by the polymer or the antiproliferative drug - contribute to the formation of high-risk vulnerable lesions within stented segments. [10-12] In this study we demonstrated for the first time that, in addition to other established predictors of neoatherosclerosis, baseline ESS - irrespective of the stent type - is involved in neoatherosclerotic lesion formation and is a predictor of neointima inflammation. Recently, we have demonstrated that neoatherosclerosis has focal manifestations with some segments appearing more vulnerable than others in developing high-risk lesions. [13] The findings of our analysis 
provide mechanistic insights about the focal manifestations of neoatherosclerosis showing that the baseline local hemodynamic forces contribute to the formation of vulnerable neo-lesions.

More importantly, we showed that segments exposed to low ESS $(<1 \mathrm{~Pa})$ at baseline have increased thrombus burden and neointima discontinuities at the index procedure, a finding which suggests that baseline local hemodynamic forces maybe a predictor of the location of the culprit lesion (supplementary Figure 4). Indeed, out of the 30 culprit lesions identified in segments where blood flow simulations was performed at the baseline models low ESS $(<1 \mathrm{~Pa})$ was found at the culprit site - defined either as the $1.5 \mathrm{~mm}$ sub-segment with neointima rupture or a the segment with the maximum neointima burden - in $73 \%$ of the cases ( 8 ruptured neoatherosclerotic plaques, 12 neoatherosclerotic plaques that resulted in a significant lumen obstruction and 2 cases of excessive neointima proliferation). It should be stressed however that in contrast to the PREDICTION study in our analysis there was no denominator, i.e., stented segments studied with OCT imaging that did not cause cardiovascular events so as to compare the hemodynamic variables in the two groups and explore whether ESS is predictor of late stent failure. [2] Therefore, further research and evidence from large scale long-term follow-up OCT studies in stented segments is needed in order to examine whether the local hemodynamic forces is a predictor of stent failure (Figure 3).

Similar to what it has been reported in native segments we found high ESS at the neointima rupture site. [6, 14] Animal studies have shown that high ESS activates matrix metalloproteinases which promote plaque degradation and destabilization. [15-16] Several reports have shown that in native segments most plaque ruptures occur in the upstream of the lesion where high ESS, axial stress and circumferential stress are noted. [6, 14] Interestingly, in this study most of the neointima ruptures occurred at the throat of the lesion. It is likely geometrical differences in plaque morphology between culprit lesions in stented and native vessels to account for this discrepancy. Experimental studies have shown that circumferential and axial stress depend not only on lesion location-i.e., upstream, throat, downstream, or shoulders - but also on the geometrical features of the lesions including remodelling pattern, plaque composition, cap thickness, and longitudinal lesion asymmetry. [17-19] Further research and implementation of fluid structure interaction modelling in a larger number of ruptured lesions in stented segments is required in order to further explore the mechanisms regulating neointima rupture. 


\section{Limitations}

There are several limitations in this study. First, the small number of the included patients, the strict inclusion criteria that were required for coronary reconstruction and the fact that we solely included consecutive patients admitted with a cardiovascular event attributed to neoatherosclerotic lesion formation and we did not have a control group do not allow us to accurately examine the incidence and distribution of neoatherosclerosis in different stent types and accurately evaluate the prognostic of implications of ESS distribution. Considering however, that a prospective large scale study that will include asymptomatic and symptomatic patients who will undergo OCT imaging many years post stent implantation is unlikely to be feasible in future, we believe that the present analysis is unique in its kind and provides valuable mechanistic insights about the role of ESS on neoatherosclerotic lesion formation.

Another limitation is the lack of OCT data at baseline that would allow us to examine the morphology and pathology of the underlying plaque and the interplay between plaque pathology, biology, tissue prolapse and ESS in the formation of lipid-rich neoatherosclerotic lesions.[10] Similar to previously published studies that investigated the implications of the local hemodynamic forces on neointima proliferation we assumed that the stent surface at follow-up corresponded to the lumen surface immediately after stent implantation. $[3,7-8]$ This assumption however did not allow us to assess the effect of strut protrusion/malapposition or edge dissection on the local hemodynamic micro-environment at baseline. Our previous experience in scaffolded segments, where strut architecture is heterogeneous, has taught us that even if the baseline OCT was available it would have been impossible to identify with accuracy in metallic stents corresponding struts between baseline and follow-up and assess in detail the implications of strut protrusion/malapposition and edge dissection on the ESS distribution and neoatherosclerotic lesion formation. [7] Besides, invasive imaging studies have shown that lumen micro-architecture changes rapidly in stented segments since edge dissections rapidly heal and most of the malapposed struts are covered at short term follow-up; therefore it is unlikely that the flow disruptions caused by these features to have a critical impact on the formation of the neoatherosclerotic lesions detected in our study at $7.4 \pm 4.8$ years post stent implantation. [20-21]

We imposed generic and non-patient specific flow characteristics in the inflow of the models, because baseline angiography was not available for most of the cases and there was TIMI flow III in coronary angiography at follow-up only in $46 \%$ of the cases. We assumed that there were no changes in the luminal dimensions of the native segments as well as in the blood flows between the index procedure and the time of the event. These assumptions are likely to affect 
the mean ESS values in the stented segments and especially at the proximal edge of the stent; but, they are unlikely to have an effect on the relative ESS distribution. Reassuringly our results were not different when we excluded from our analysis the first $3 \mathrm{~mm}$ from each stented segment (supplementary Table 2).

Finally, side branches were not incorporated in the 3D models as the methodology that has been implemented in our study did not enable reconstruction of the side branches. Recently it has been shown that side branches affects the ESS distribution in the main vessel, nevertheless it is unclear whether the addition of side branches in the 3D model would increase the accuracy of the ESS in predicting vulnerable segments.[22]

\section{Conclusions}

Local hemodynamic forces, in particular ESS distribution irrespective of stent type, appear to regulate late vessel response following DES implantation, neoatherosclerotic lesion formation and neoatherosclerotic plaque rupture. Further research is required to explore whether optimal ESS distribution post stent implantation can improve long-term clinical outcomes.

\section{Acknowledgement}

None. 


\section{References}

[1] Thondapu V, Bourantas CV, Foin N, Jang IK, Serruys PW, Barlis P. Biomechanical stress in coronary atherosclerosis: emerging insights from computational modelling. Eur Heart J. 2016.

[2] Shishido K, Antoniadis AP, Takahashi S, Tsuda M, Mizuno S, Andreou I, et al. Effects of Low Endothelial Shear Stress After Stent Implantation on Subsequent Neointimal Hyperplasia and Clinical Outcomes in Humans. J Am Heart Assoc. 2016;5.

[3] Papafaklis MI, Bourantas CV, Theodorakis PE, Katsouras CS, Naka KK, Fotiadis DI, et al. The effect of shear stress on neointimal response following sirolimus- and paclitaxel-eluting stent implantation compared with bare-metal stents in humans. JACC Cardiovasc Interv. 2010;3:1181-9.

[4] van der Giessen A, Wentzel J, Groen H, de Feyter P, van de Vosse FV, van der Steen A, et al. Location of plaque ulceration in human coronary arteries is related to shear stress. In: Proceedings of the Asme Summer Bioengineering Conference. 2010:31-2.

[5] Papafaklis MI, Bourantas CV, Yonetsu T, Vergallo R, Kotsia A, Nakatani S, et al. Anatomically correct threedimensional coronary artery reconstruction using frequency domain optical coherence tomographic and angiographic data: head-to-head comparison with intravascular ultrasound for endothelial shear stress assessment in humans. EuroIntervention. 2015;11:407-15.

[6] Gijsen F, van der Giessen A, van der Steen A, Wentzel J. Shear stress and advanced atherosclerosis in human coronary arteries. J Biomech. 2013;46:240-7.

[7] Bourantas CV, Papafaklis MI, Kotsia A, Farooq V, Muramatsu T, Gomez-Lara J, et al. Effect of the endothelial shear stress patterns on neointimal proliferation following drug-eluting bioresorbable vascular scaffold implantation: an optical coherence tomography study. JACC Cardiovasc Interv. 2014;7:315-24.

[8] Bourantas CV, Raber L, Zaugg S, Sakellarios A, Taniwaki M, Heg D, et al. Impact of local endothelial shear stress on neointima and plaque following stent implantation in patients with ST-elevation myocardial infarction: A subgroupanalysis of the COMFORTABLE AMI-IBIS 4 trial. Int J Cardiol. 2015;186:178-85.

[9] Raber L, Wohlwend L, Wigger M, Togni M, Wandel S, Wenaweser P, et al. Five-year clinical and angiographic outcomes of a randomized comparison of sirolimus-eluting and paclitaxel-eluting stents: results of the Sirolimus-Eluting Versus Paclitaxel-Eluting Stents for Coronary Revascularization LATE trial. Circulation. 2011;123:2819-28, $6 \mathrm{p}$ following 28 . 
[10] Nakazawa G, Otsuka F, Nakano M, Vorpahl M, Yazdani SK, Ladich E, et al. The pathology of neoatherosclerosis in human coronary implants bare-metal and drug-eluting stents. J Am Coll Cardiol. 2011;57:1314-22.

[11] Taniwaki M, Windecker S, Zaugg S, Stefanini GG, Baumgartner S, Zanchin T, et al. The association between instent neoatherosclerosis and native coronary artery disease progression: a long-term angiographic and optical coherence tomography cohort study. Eur Heart J. 2015;36:2167-76.

[12] Yonetsu T, Kato K, Kim SJ, Xing L, Jia H, McNulty I, et al. Predictors for neoatherosclerosis: a retrospective observational study from the optical coherence tomography registry. Circ Cardiovasc Imaging. 2012;5:660-6.

[13] Stettler R, Dijkstra J, Raber L, Torii R, Zhang YJ, Karanasos A, et al. Neointima and neoatherosclerotic characteristics in bare metal and first and second generation drug eluting stents in patients admitted with cardiovascular events attributed to stent failure: an optical coherence tomography study. EuroIntervention. 2017.

[14] Fukumoto Y, Hiro T, Fujii T, Hashimoto G, Fujimura T, Yamada J, et al. Localized elevation of shear stress is related to coronary plaque rupture: a 3-dimensional intravascular ultrasound study with in-vivo color mapping of shear stress distribution. J Am Coll Cardiol. 2008;51:645-50.

[15] Tronc F, Mallat Z, Lehoux S, Wassef M, Esposito B, Tedgui A. Role of matrix metalloproteinases in blood flowinduced arterial enlargement: interaction with NO. Arterioscler Thromb Vasc Biol. 2000;20:E120-6.

[16] Castier Y, Brandes RP, Leseche G, Tedgui A, Lehoux S. p47phox-dependent NADPH oxidase regulates flowinduced vascular remodeling. Circ Res. 2005;97:533-40.

[17] Lee JM, Choi G, Hwang D, Park J, Kim HJ, Doh JH, et al. Impact of Longitudinal Lesion Geometry on Location of Plaque Rupture and Clinical Presentations. JACC Cardiovasc Imaging. 2016.

[18] Imoto K, Hiro T, Fujii T, Murashige A, Fukumoto Y, Hashimoto G, et al. Longitudinal structural determinants of atherosclerotic plaque vulnerability: a computational analysis of stress distribution using vessel models and threedimensional intravascular ultrasound imaging. J Am Coll Cardiol. 2005;46:1507-15.

[19] Kumar RK, Balakrishnan KR. Influence of lumen shape and vessel geometry on plaque stresses: possible role in the increased vulnerability of a remodelled vessel and the "shoulder" of a plaque. Heart. 2005;91:1459-65.

[20] Radu MD, Raber L, Heo J, Gogas BD, Jorgensen E, Kelbaek H, et al. Natural history of optical coherence tomography-detected non-flow-limiting edge dissections following drug-eluting stent implantation. EuroIntervention. 2014;9:1085-94. 
[21] Gutierrez-Chico JL, Wykrzykowska J, Nuesch E, van Geuns RJ, Koch KT, Koolen JJ, et al. Vascular tissue reaction to acute malapposition in human coronary arteries: sequential assessment with optical coherence tomography. Circ Cardiovasc Interv. 2012;5:20-9, S1-8.

[22] Stone PH, Coskun AU, Prati F. Ongoing Methodological Approaches to Improve the In Vivo Assessment of Local Coronary Blood Flow and Endothelial Shear Stress: The Devil Is in the Details. J Am Coll Cardiol. 2015;66:136-8. 
Table 1. Baseline characteristics of the patients included in the neoatherosclerosis analysis.

\begin{tabular}{|c|c|c|c|c|}
\hline & $\begin{array}{l}\text { BMS } \\
(n=11)\end{array}$ & $\begin{array}{l}\text { 1st gen DES } \\
(\mathrm{n}=12)\end{array}$ & $\begin{array}{l}\text { 2nd gen DES } \\
(n=11)\end{array}$ & $\mathbf{P}$ \\
\hline \multicolumn{5}{|l|}{ Baseline characteristics } \\
\hline Age (years) & $60.1 \pm 8.5$ & $56.5 \pm 8.2$ & $63.2 \pm 9.5$ & 0.711 \\
\hline Time interval (years) & $12.2 \pm 2.9$ & $7.6 \pm 3.0$ & $2.4 \pm 2.6$ & $<0.001$ \\
\hline Male & $10(91 \%)$ & $9(75 \%)$ & $6(55 \%)$ & 0.153 \\
\hline Hypertension & $8(73 \%)$ & $9(75 \%)$ & $7(64 \%)$ & 0.822 \\
\hline Diabetes mellitus & $3(27 \%)$ & $3(25 \%)$ & $6(55 \%)$ & 0.266 \\
\hline Dyslipidemia & $10(91 \%)$ & $8(67 \%)$ & $7(64 \%)$ & 0.279 \\
\hline Smoking & $8(73 \%)$ & $4(33 \%)$ & $7(64 \%)$ & 0.135 \\
\hline Prior MI & $8(73 \%)$ & $5(42 \%)$ & $5(46 \%)$ & 0.274 \\
\hline Number of diseased vessels & $2(1-3)$ & $1(1-2)$ & $2(1-2)$ & 0.267 \\
\hline Clinical presentation & & & & 0.949 \\
\hline Stable angina & $2(18 \%)$ & $3(25 \%)$ & $2(18 \%)$ & \\
\hline NSTEMI & $7(64 \%)$ & $7(58 \%)$ & $8(73 \%)$ & \\
\hline STEMI & $2(12 \%)$ & $2(17 \%)$ & $1(9 \%)$ & \\
\hline Treated vessel & & & & 0.131 \\
\hline Left main stem & $0(0 \%)$ & $0(0 \%)$ & $2(18 \%)$ & \\
\hline Left anterior descending artery & $7(64 \%)$ & $8(67 \%)$ & $5(46 \%)$ & \\
\hline Left circumflex & $4(36 \%)$ & $1(8 \%)$ & $3(27 \%)$ & \\
\hline Right coronary artery & $0(0 \%)$ & $3(25 \%)$ & $1(9 \%)$ & \\
\hline \multicolumn{5}{|l|}{ Baseline procedural characteristics } \\
\hline Length of stented segment (mm) & $22.6 \pm 6.4$ & $23.8 \pm 10.5$ & $37.4 \pm 12.9$ & 0.004 \\
\hline Diameter of stent (mm) & $3.00(3.00-3.50)$ & $3.00(2.75-3.50)$ & $3.00(2.75-3.50)$ & 0.960 \\
\hline Number of stents & $1(1-1)$ & $1(1-2)$ & $1(1-2)$ & 0.080 \\
\hline
\end{tabular}

BMS, bare metal stent; DES, drug eluting stent; MI, myocardial infarction; NSTEMI, non-ST elevation myocardial infarction; STEMI, ST elevation myocardial infarction. 
Table 2. Association between ESS and atherosclerotic characteristics.

\begin{tabular}{|c|c|c|}
\hline & $\beta(95 \% \mathrm{CI})$ & $\mathbf{P}$ \\
\hline \multicolumn{3}{|l|}{ Plaque characteristics } \\
\hline Mean neointima area $\left(\mathrm{mm}^{2}\right)$ & $-0.38(-0.50,-0.26)$ & $<0.001$ \\
\hline Neointima burden (\%) & $-5.01(-6.77,-3.21)$ & $<0.001$ \\
\hline Incidence of neoatherosclerosis (\%) & $-0.60(-0.96,-0.27)$ & $<0.001$ \\
\hline Mean neoatherosclerotic area $\left(\mathrm{mm}^{2}\right)$ & $-0.18(-0.26,-0.10)$ & $<0.001$ \\
\hline Mean neoatherosclerotic burden (\%) & $-4.05(-6.04,-1.95)$ & $<0.001$ \\
\hline Incidence of lipid-rich neointima (\%) & $-0.54(-0.95,-0.17)$ & 0.005 \\
\hline Mean lipid area $\left(\mathrm{mm}^{2}\right)$ & $-0.17(-0.25,-0.09)$ & $<0.001$ \\
\hline Lipid burden (\%) & $-3.60(-5.54,-1.58)$ & $<0.001$ \\
\hline Minimum fibrous cap thickness $(\mu \mathrm{m})$ & $-15.8(-34.6,2.3)$ & 0.104 \\
\hline Incidence of TCFA & $-0.05(-0.54,0.39)$ & 0.833 \\
\hline Incidence of calcium-rich neointima (\%) & $-0.82(-1.51,-0.21)$ & 0.014 \\
\hline Mean calcific area $\left(\mathrm{mm}^{2}\right)$ & $-0.01(-0.24,0.01)$ & 0.269 \\
\hline Calcific burden (\%) & $-0.47(-1.05,0.11)$ & 0.111 \\
\hline Incidence of macrophages (\%) & $-0.87(-1.39,-0.40)$ & $<0.001$ \\
\hline Incidence of cholesterol crystal (\%) & $0.50(-1.14,2.11)$ & 0.479 \\
\hline Incidence neo-vessels (\%) & $-0.94(-2.82,0.50)$ & 0.272 \\
\hline Incidence of neointima discontinuities (\%) & $-0.88(-2.29,0.25)$ & 0.174 \\
\hline Incidence of thrombus (\%) & $-1.46(-2.61,-0.47)$ & 0.007 \\
\hline
\end{tabular}

ESS, endothelial shear stress; TCFA, thin cap fibroatheroma. 

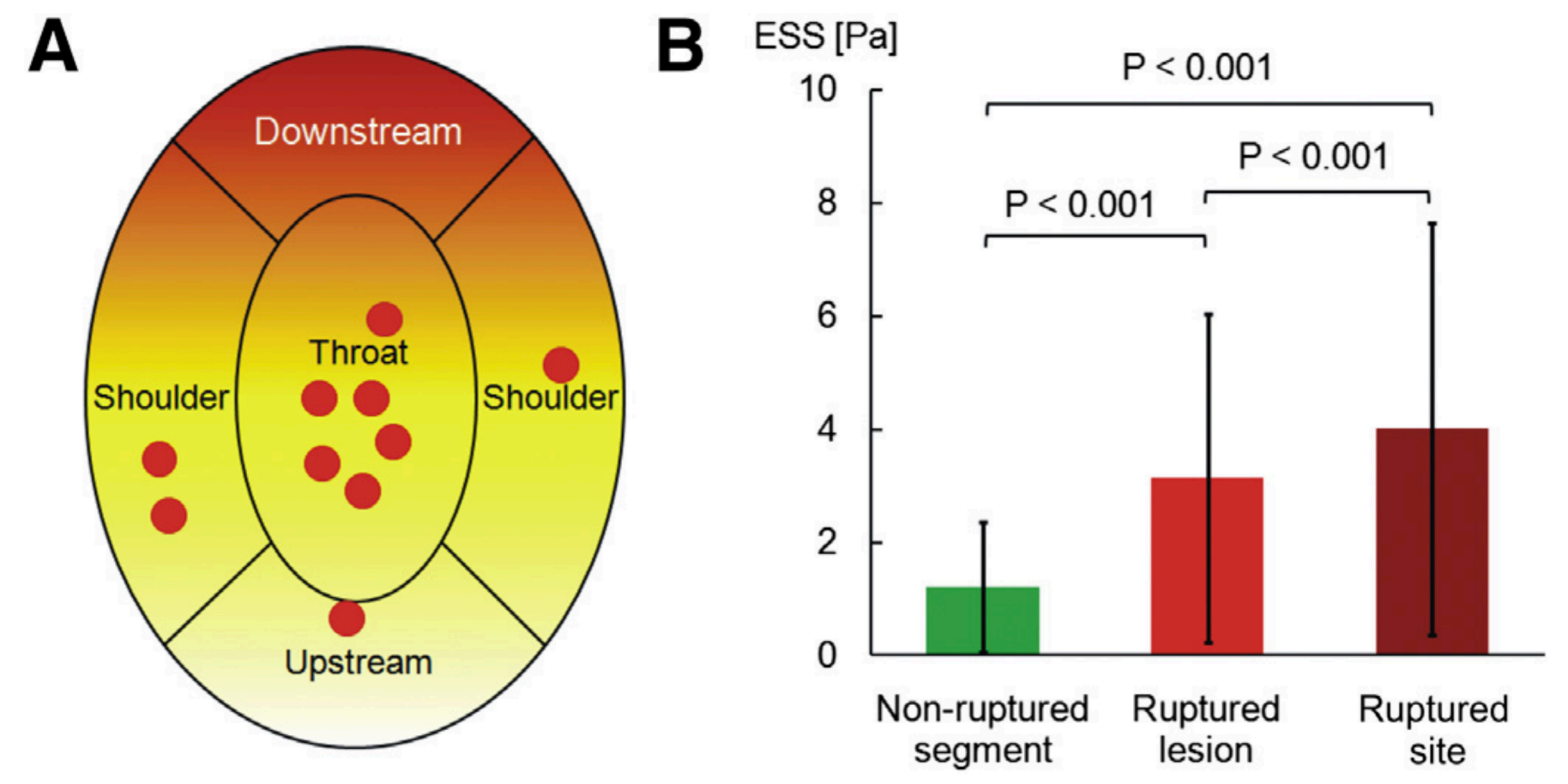

Figure 1. Comparison of the incidence of neoatherosclerosis (A), lipid-rich neointima (B), calcific-rich neointima (C), macrophage accumulations (D), neointima discontinuities (E) and thrombus (F) in segments exposed to low baseline ESS and normal/high ESS. 


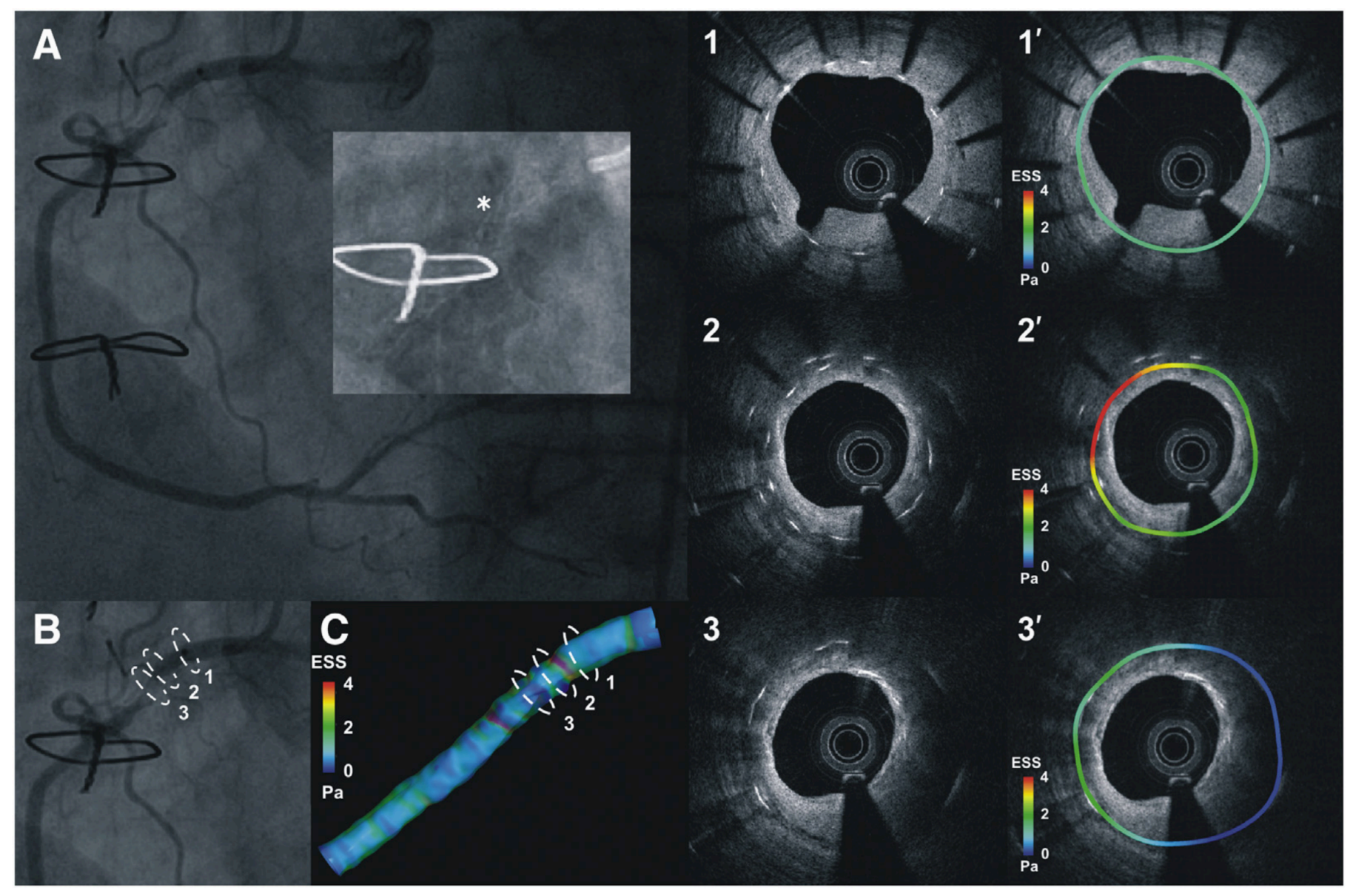

Figure 2. Case example illustrating the long-term implications of the baseline local hemodynamic forces in a stented segment. Panel (A) illustrates the angiographic image of a patientadmitted with non-ST elevation myocardial infarction, attributed to stent failure. The patient had BMS implantation in the right coronary artery 14 years ago. Magnified view of the stented segment - the grayscale colours have been inverted - allows identification of stent underexpansion indicated with an asterisk. Panel B shows the location of the OCT images $(1,2,3)$ acquired before PCI while panel C the stent (in a transparent fashion) and lumen models reconstructed from the fusion of the angiographic and OCT imaging data. The ESS distribution in the stented surface is colour coded displayed. Normal ESS noted at the proximal stent $\left(1^{\prime}\right)$, while at the stent overlapping and underexpansion site the ESS values are increased (2'). In contrary to frames $(1,2)$ where the neointima is limited in frame (3) that is located distally to the underexpanded segment there is a neoatherosclerotic lesion and the baseline ESS have low values (3'). 


\title{
Supplement
}

\section{Implications of the local hemodynamic forces on the formation and}

\section{destabilization of neoatherosclerotic lesions}

Ryo Torii, ${ }^{1} \mathrm{PhD}$; Rodrigue Stettler, ${ }^{2} \mathrm{MD}$; Lorenz Räber, ${ }^{3} \mathrm{MD}, \mathrm{PhD}$; Yao-Jun Zhang, ${ }^{4} \mathrm{MD}, \mathrm{PhD}$; Antonis Karanasos, ${ }^{5} \mathrm{MD}$ PhD; Jouke Dijkstra, ${ }^{6} \mathrm{PhD}$; Kush Patel, ${ }^{2} \mathrm{MBBS}$; Tom Crake, ${ }^{2} \mathrm{MD}$, FRCP; Steve Hamshere, ${ }^{2}$ MBBS; Hector M. Garcia-Garcia, ${ }^{5} \mathrm{MD}$, PhD; Erhan Tenekecioglu, ${ }^{5} \mathrm{MD}, \mathrm{PhD}$; Muhiddin Ozkor, ${ }^{2}$ MD, BSc; Andreas Baumbach,,${ }^{2,7}$ MD, FRCP; Stephan Windecker, ${ }^{3}$ MD; Patrick W. Serruys, ${ }^{5,8} \mathrm{MD}$, PhD; Evelyn Regar, ${ }^{5} \mathrm{MD}$, PhD; Anthony Mathur, ${ }^{2,7} \mathrm{MD}, \mathrm{PhD}$; Christos V.

$$
\text { Bourantas, }{ }^{2,7,9, *} \mathrm{MD}, \mathrm{PhD}
$$

\footnotetext{
${ }^{1}$ Department of Mechanical Engineering, University College London, London, United Kingdom

${ }^{2}$ Barts Heart Centre, Barts Health NHS, London, United Kingdom

${ }^{3}$ Bern University Hospital, Bern, Switzerland

${ }^{4}$ Nanjing First Hospital, Nanjing Medical University, Nanjing, China

${ }^{5}$ Thoraxcenter, Erasmus Medical Centre, Rotterdam, The Netherlands

${ }^{6}$ Leiden University Medical Centre, Leiden, The Netherlands

${ }^{7}$ Queen Mary University London, London, United Kingdom

${ }^{8}$ Faculty of Medicine, National Heart \& Lung Institute, Imperial College London, United Kingdom

${ }^{9}$ Institute of Cardiovascular Sciences, University College London, London, United Kingdom
}

\author{
*Address for correspondence \\ Christos V. Bourantas, MD, PhD: Consultant cardiologist Barts, Heart Centre, $1^{\text {st }}$ St Martin's le \\ Grand, London EC1A 7BE, United Kingdom \\ e-mail: Christos.Bourantas@bartshealth.nhs.uk; Tel: +44 208535 6736, Fax: +44 2085356690
}


Assessment of neointima characteristics in optical coherence tomographic images

Neoatherosclerosis was defined as neointima containing lipid or calcific tissue. Lipid tissue was defined as a low signal intensity region with diffuse borders and increased signal attenuation while calcific tissue was characterised as a low backscattering heterogeneous region with well-defined borders.[1-2] In each frame the borders of the lipid and calcific tissue were detected and the lipid and calcific area were estimated (supplementary Figure 6). In case that the lipid / calcific tissue was extended beyond the neointima its distal border was defined by the stent struts. A semi-automated methodology (QCM-CMS) was used to identify the border of the fibrous cap over lipid tissue and the minimum cap thickness were estimated.[3] Thin-cap fibroatheroma (TCFA) was defined as lipid tissue with a fibrous cap thickness $\leq 65 \mu \mathrm{m}$ while lipid tissue with a cap thickness $>65 \mu \mathrm{m}$ was characterised as fibroatheroma.

Macrophages were defined as punctuated or signal-rich regions with a strong signal attenuation behind them, neo-vessels were characterised as small thin black holes (diameter $\leq 300 \mu \mathrm{m}$ ) that were not connected with the lumen and were seen in the neointima in three consecutive frames, cholesterol crystals were defined as linear regions will high signal intensity, whereas thrombus was classified as a mass in the lumen or attached to the lumen surface.[1, 4-5] Finally neointima discontinuities were classified as disruptions of the neointima and included flaps, cavities, double lumen and fissures.[6]

\section{Blood flow simulation}

Blood flow simulation was performed in the three dimensional (3D) geometry corresponding to the lumen surface at baseline and, if neointima discontinuities were present, to the $3 \mathrm{D}$ geometry corresponding to the lumen surface before the cardiovascular event (pre-rupture model). The models were meshed into tetrahedral and prismatic cells, and the ESS was estimated by solving the 3D Navier-Stokes equations. The blood was assumed to be a homogeneous, Newtonian fluid with a dynamic viscosity of $0.0035 \mathrm{~Pa} \cdot \mathrm{s}$ and a density of $1,050 \mathrm{~kg} / \mathrm{m}^{3}$. Blood flow was considered to be laminar and incompressible. A steady inflow with parabolic velocity profile was specified as the inflow boundary condition, as there is evidence indicating that there is insignificant difference in the 
ESS estimated when a steady or a pulsatile flow profile is used.[7-8] An inflow of $1.0 \mathrm{ml} / \mathrm{s}$ was assumed for all patients, approximating the average healthy coronary flow.[9] To allow the flow to be fully developed at the entrance of the OCT-based model, an extension of 10 vessel diameter length was added at the inlet. The arterial wall was considered to be rigid non-permeable, and no-slip conditions were applied at the luminal surface. At the outlet of each vessel, zero relative pressure was prescribed. The size of the mesh was optimised after a careful sensitivity test. Meshing and computations were carried out using ANSYS ICEM CFD and ANSYS CFX version 17.1 (ANSYS Inc. Canonsburg, PA, USA). 


\section{References}

[1] Tearney GJ, Regar E, Akasaka T, Adriaenssens T, Barlis P, Bezerra HG, et al. Consensus standards for acquisition, measurement, and reporting of intravascular optical coherence tomography studies: a report from the International Working Group for Intravascular Optical Coherence Tomography Standardization and Validation. Journal of the American College of Cardiology. 2012;59:1058-72.

[2] Prati F, Regar E, Mintz GS, Arbustini E, Di Mario C, Jang IK, et al. Expert review document on methodology, terminology, and clinical applications of optical coherence tomography: physical principles, methodology of image acquisition, and clinical application for assessment of coronary arteries and atherosclerosis. Eur Heart J. 2010;31:401-15.

[3] Radu MD, Yamaji K, Garcia-Garcia HM, Zaugg S, Taniwaki M, Koskinas KC, et al. Variability in the measurement of minimum fibrous cap thickness and reproducibility of fibroatheroma classification by optical coherence tomography using manual versus semi-automatic assessment. EuroIntervention. 2016;12:e987-e97.

[4] Vorpahl M, Nakano M, Virmani R. Small black holes in optical frequency domain imaging matches intravascular neoangiogenesis formation in histology. Eur Heart J. 2010;31:1889.

[5] Uemura S, Ishigami K, Soeda T, Okayama S, Sung JH, Nakagawa H, et al. Thin-cap fibroatheroma and microchannel findings in optical coherence tomography correlate with subsequent progression of coronary atheromatous plaques. Eur Heart J. 2012;33:78-85.

[6] Bourantas CV, Serruys PW, Nakatani S, Zhang YJ, Farooq V, Diletti R, et al. Bioresorbable vascular scaffold treatment induces the formation of neointimal cap that seals the underlying plaque without compromising the luminal dimensions: a concept based on serial optical coherence tomography data. EuroIntervention. 2015;11:746-56.

[7] Feldman CL, Ilegbusi OJ, Hu Z, Nesto R, Waxman S, Stone PH. Determination of in vivo velocity and endothelial shear stress patterns with phasic flow in human coronary arteries: a methodology to predict progression of coronary atherosclerosis. Am Heart J. 2002;143:931-9.

[8] Tenekecioglu E, Torii R, Bourantas C, Crake T, Zeng Y, Sotomi Y, et al. Preclinical assessment of the endothelial shear stress in porcine-based models following implantation of two different 
bioresorbable scaffolds: effect of scaffold design on the local haemodynamic micro-environment. EuroIntervention. 2016;12.

[9] Nichols WW, O’Rourke MF. Theoretical, Experimental and Clinical Principles. In: McDonald's, editor. Blood Flow in Arteries. London: Arnold; 1998. 


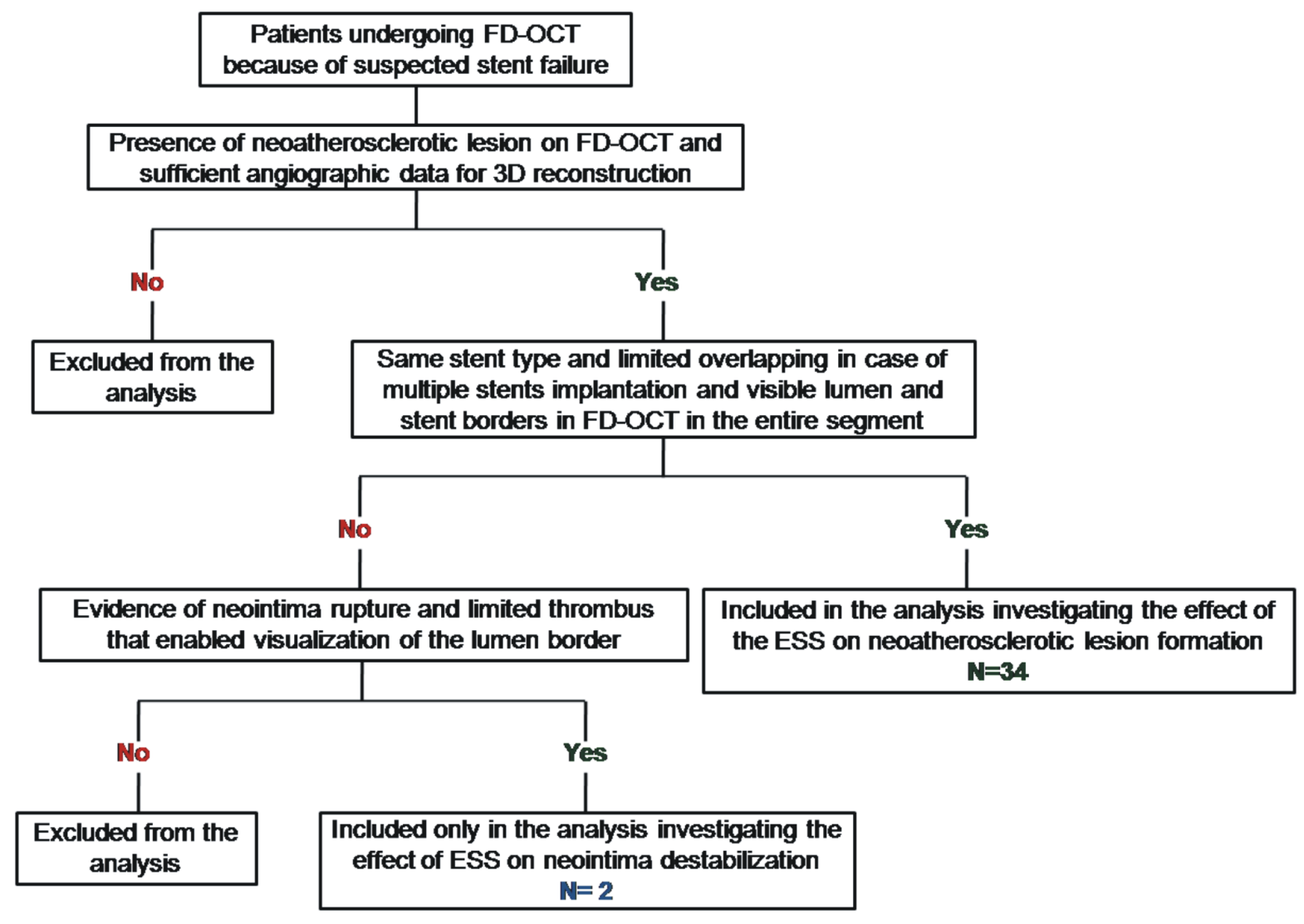

Supplementary Figure 1. Flowchart of study design. 

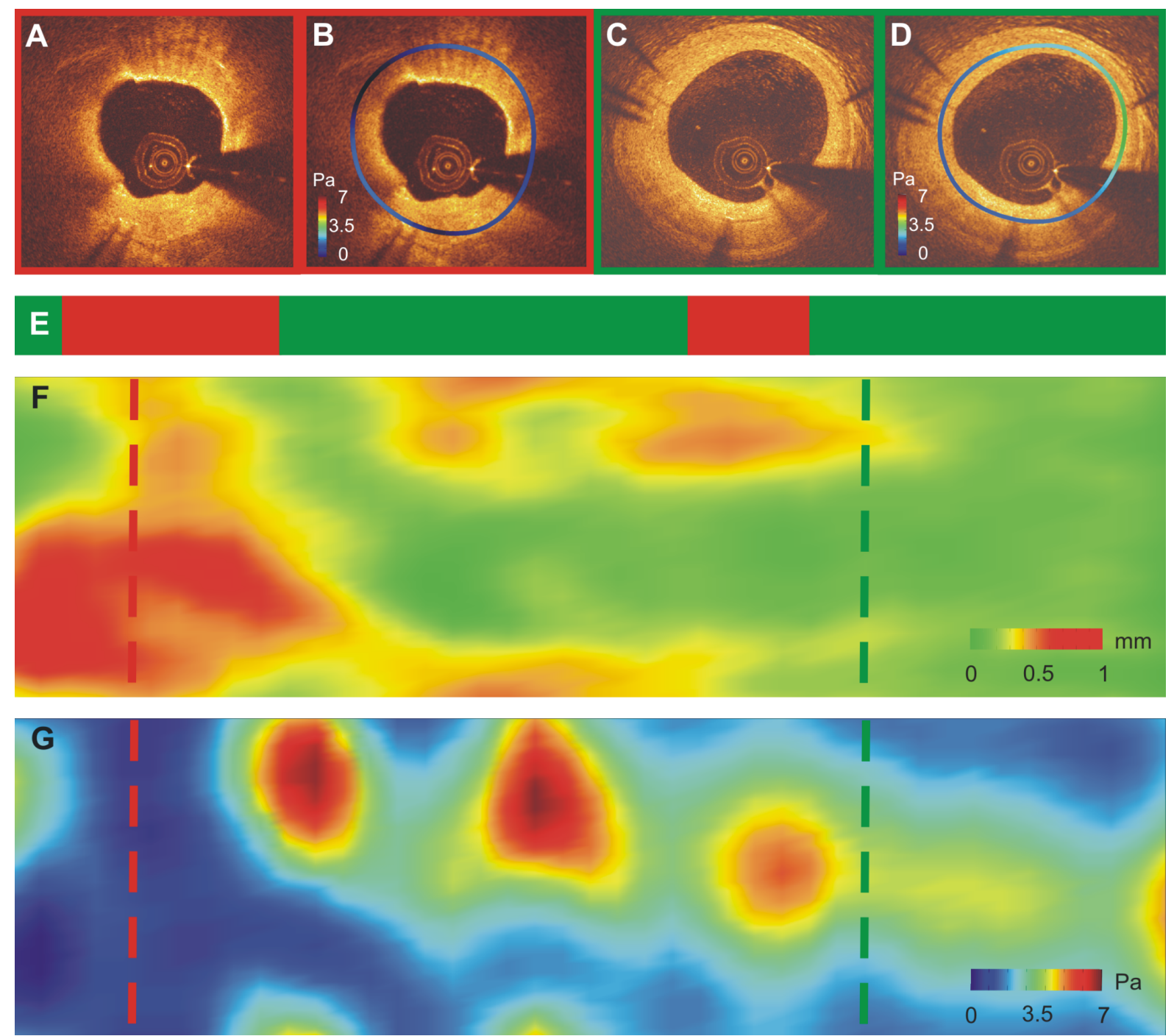

Supplementary Figure 2. OCT images portraying a neoatherosclerotic lipid-rich lesion (A) and

fibrotic neointima (C) in a patient admitted with a non-ST elevation myocardial infarction 5 years post BMS implantation. Panels (B) and (D) portray the ESS distribution in the stent borders which represent the baseline lumen surface. Panel (E) portrays tissue characteristics along the stent segments: green bars indicate fibrotic neointima while red bars lipid-rich neointima; panel (F) is a shows the distribution of the neointima thickness along the stented segment (green indicates minimal/no neointima and yellow/red increased neointima) while (G) the ESS distribution in the baseline lumen surface (blue indicates low ESS and red high ESS values). There is a spatial correspondence of segments exposed to low ESS at baseline with increased neointima burden and neoatherosclerotic lipid-rich lesions at follow-up. 


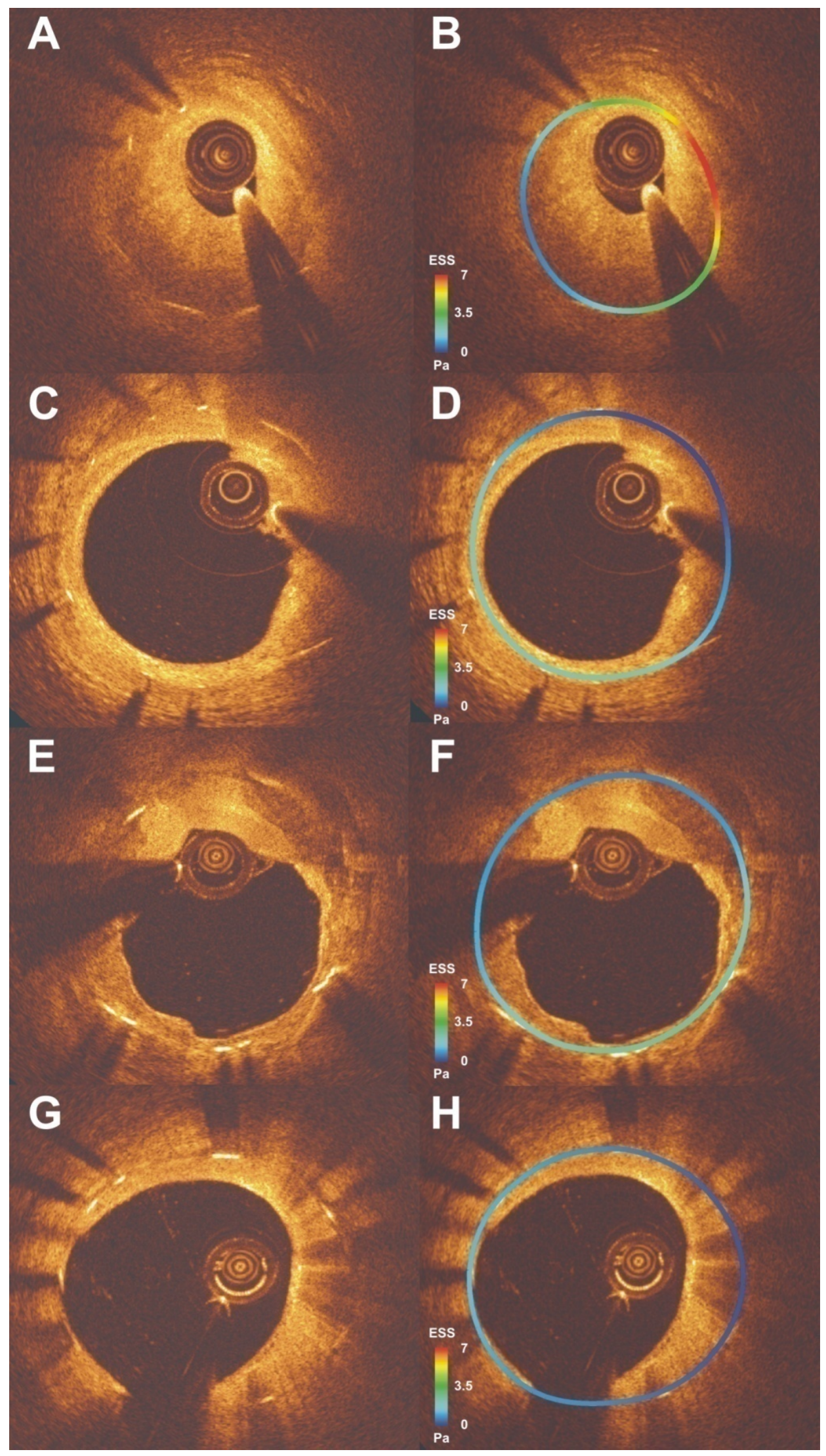

Supplementary Figure 3. OCT cross sections portraying: (A) a segment with an increased neointima burden, (C) lipid-rich neointima with white thrombus, (E) calcific-rich neointima (extending from 12 
till 10 o'clock covering almost the entire circumference of the neointima, and (G) macrophage accumulations. Panels (B, D, F, H) portray the corresponding sections with the ESS distribution in the stent surface. Regions exposed to low ESS at baseline corresponded to increased neointima, lipid-rich neointima and macrophage accumulations at follow-up while the distribution of the calcific tissue was not affected by the ESS. 


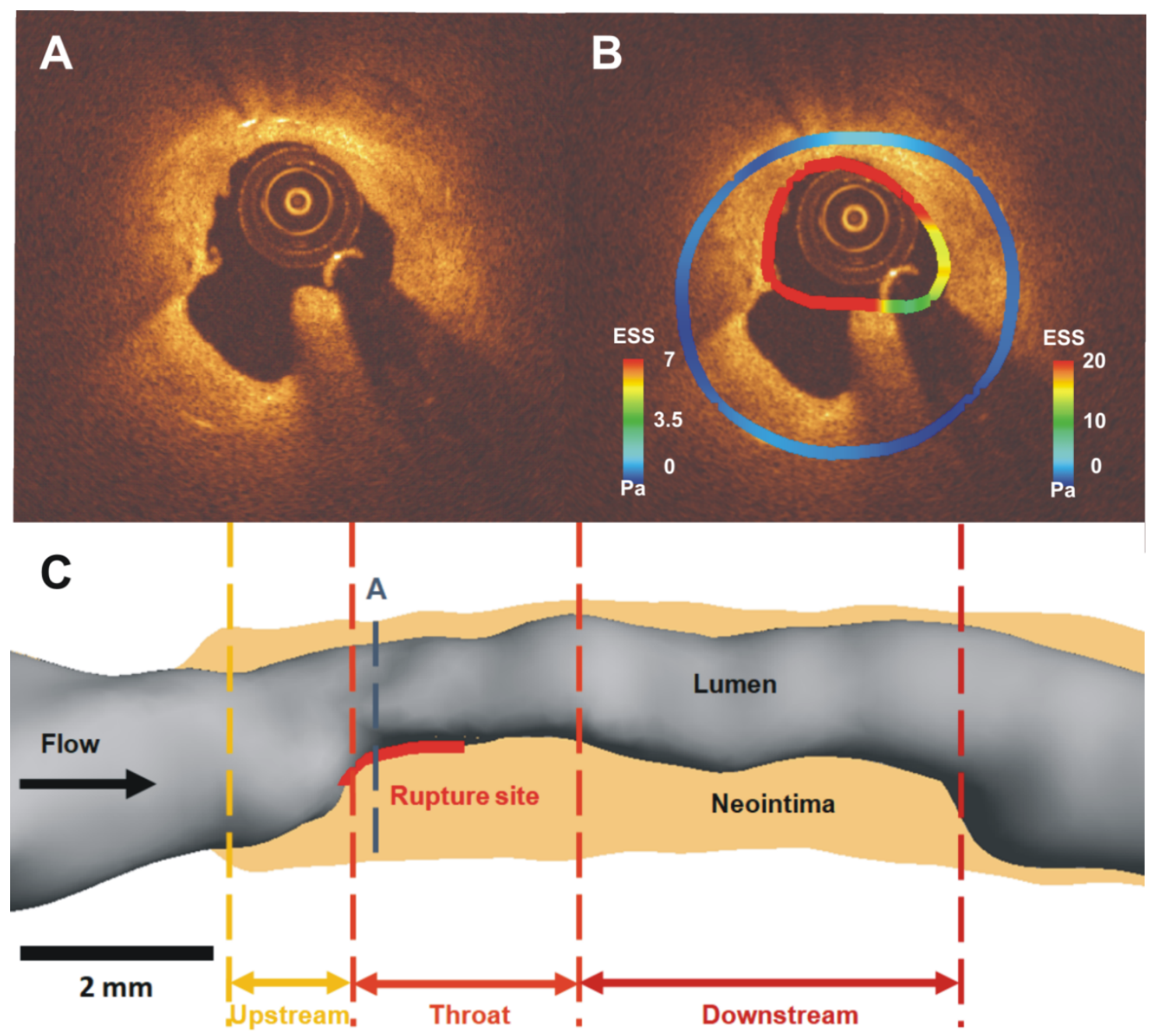

Supplementary Figure 4. A case example of neointima rupture indicated by the presence of a cavity at 6 o' clock (A). As it is shown in panel (B) the baseline ESS was low creating an athero-promoting hemodynamic environment (the scale bar for the baseline ESS is shown in the left-bottom side of panel B). Conversely, high ESS was noted at the luminal surface before neointima rupture (the scale bar for the ESS before neointima rupture is shown in the left-bottom side of panel B). Panel (C) shows a longitudinal section of the neoatherosclerotic lesion before its rupture. The borders of the upstream, throat and downstream segments of the lesion are indicted with yellow, orange and red dashed lines, the location of the frame shown in panel A with a blue dashed line, while the ruptured site in indicated with a red line. It is apparent that the mature neoatherosclerotic plaque has an increased burden that caused significant lumen stenosis. 


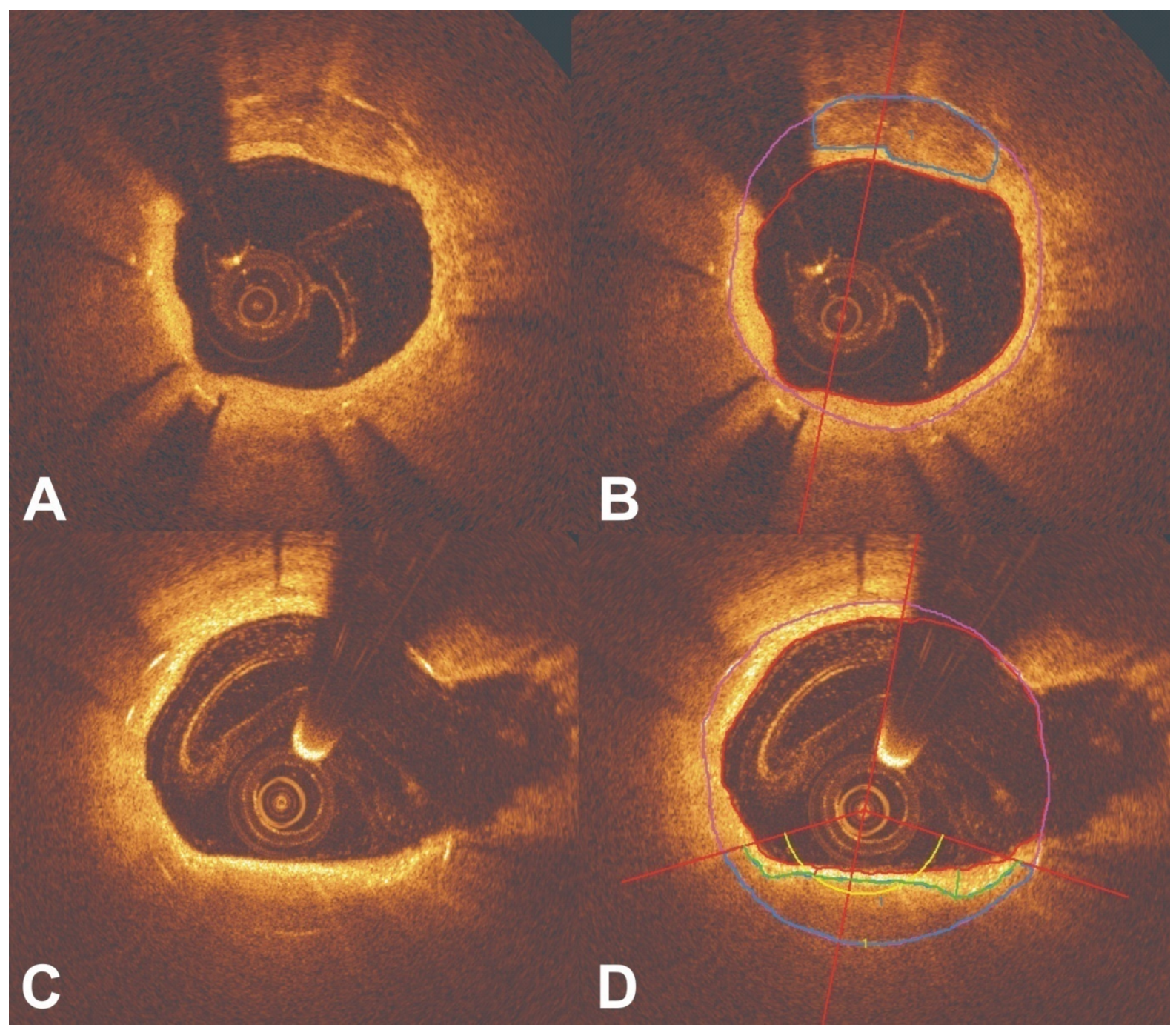

Supplementary Figure 5. Analysis of the OCT images (A, C). The lumen and the stent borders are detected by two analysts. In frames with calcific tissue in the neointima the calcific tissue borders are delineated. When the guidewire artefact $(*)$ masks the lateral extremity of the calcific tissue then its border is defined by the guidewire artefact (B). In frames portraying lipid tissue the lateral extremities of the lipid tissue are defined, then the fibrous cap is detected using a semi-automated methodology and the minimum cap thickness is automatically extracted. The lipid borders are manually annotated and defined by the cap border the lateral extremities of the lipid tissue and the stent border (D). 
Supplementary Table 1. Baseline demographics of patients with neointima disruptions.

\begin{tabular}{lc} 
& $\begin{array}{r}\text { Studied patients } \\
(\mathbf{n}=\mathbf{1 0})\end{array}$ \\
\hline Baseline characteristics & \\
\hline Age (years) & $58.7 \pm 7.6$ \\
Time interval (years) & $6.6 \pm 3.4$ \\
Male & $8(80 \%)$ \\
Hypertension & $6(60 \%)$ \\
Diabetes mellitus & $3(30 \%)$ \\
Dyslipidemia & $6(60 \%)$ \\
Smoking & $6(60 \%)$ \\
Prior MI & $5(50 \%)$ \\
Number of diseased vessels & $2(1-2)$
\end{tabular}

\begin{tabular}{ll}
\hline Clinical presentation & \\
\hline Stable angina & $1(10 \%)$ \\
NSTEMI & $6(60 \%)$ \\
STEMI & $3(30 \%)$
\end{tabular}

\begin{tabular}{ll}
\hline Treated vessel & \\
\hline Left main stem & $0(0 \%)$ \\
Left anterior descending artery & $6(60 \%)$ \\
Left circumflex & $2(20 \%)$ \\
Right coronary artery & $2(20 \%)$
\end{tabular}

\begin{tabular}{lc}
\hline Baseline procedural characteristics \\
\hline Length of stented segment $(\mathrm{mm})$ & $18.0(18.0-24.0)$ \\
Diameter of stent $(\mathrm{mm})$ & $3.15 \pm 0.52$ \\
Number of stents & $2(2-2)$ \\
\hline
\end{tabular}


Table footnote: BMS, bare metal stent; DES, drug eluting stent; MI, myocardial infarction; STEMI, ST elevation myocardial infarction; NSTEMI, non-ST elevation myocardial infarction. 
Supplementary Table 2. Association between ESS and atherosclerotic characteristics after excluding from the analysis the proximal $3 \mathrm{~mm}$ segment from each stented segment.

\begin{tabular}{|c|c|c|}
\hline & $\beta(95 \%$ CI $)$ & $\mathbf{P}$ \\
\hline \multicolumn{2}{|l|}{ Plaque characteristics } & \\
\hline Mean neointima area $\left(\mathrm{mm}^{2}\right)$ & $-0.56(-0.75,-0.38)$ & $<0.001$ \\
\hline Neointima burden $(\%)$ & $-8.14(-10.9,-5.42)$ & $<0.001$ \\
\hline Incidence of neoatherosclerosis (\%) & $-1.21(-1.75,-0.70)$ & $<0.001$ \\
\hline Mean neoatherosclerotic area $\left(\mathrm{mm}^{2}\right)$ & $-0.27(-0.40,-0.15)$ & $<0.001$ \\
\hline Mean neoatherosclerotic burden (\%) & $-5.67(-8.93,-2.53)$ & $<0.001$ \\
\hline Incidence of lipid-rich neointima (\%) & $-1.25(-1.90,-0.66)$ & $<0.001$ \\
\hline Mean lipid area $\left(\mathrm{mm}^{2}\right)$ & $-0.26(-0.38,-0.14)$ & $<0.001$ \\
\hline Lipid burden $(\%)$ & $-5.19(-8.34,-2.12)$ & 0.001 \\
\hline Minimum fibrous cap thickness $(\mu \mathrm{m})$ & $-24.2(-53.9,4.1)$ & 0.115 \\
\hline Incidence of TCFA & $-0.26(-1.02,0.44)$ & 0.475 \\
\hline Incidence of calcium-rich neointima (\%) & $-0.52(-1.32,0.21)$ & 0.179 \\
\hline Mean calcific area $\left(\mathrm{mm}^{2}\right)$ & $-0.01(-0.04,0.01)$ & 0.416 \\
\hline Calcific burden $(\%)$ & $-0.41(-1.36,0.55)$ & 0.390 \\
\hline Incidence of cholesterol crystal (\%) & $1.76(-0.59,5.19)$ & 0.188 \\
\hline Incidence neo-vessels (\%) & $-0.02(-0.05,0.00)$ & 0.098 \\
\hline Incidence of macrophages (\%) & $-1.33(-2.05,-0.66)$ & $<0.001$ \\
\hline Incidence of neointima discontinuities (\%) & $-0.02(-0.05,0.01)$ & 0.019 \\
\hline Incidence of thrombus (\%) & $-1.77(-3.23,-0.49)$ & 0.010 \\
\hline
\end{tabular}

Table footnote: TCFA, thin cap fibroatheroma. 